\title{
Abundância e locais de ocorrência do jacaré-de-papo-amarelo (Caiman latirostris, Alligatoridae) no noroeste da Ilha de Santa Catarina, SC
}

\author{
Roberto Fusco-Costa ${ }^{1 *}$ \\ Tânia Tarabini Castellani² \\ Walfrido Moraes Tomás ${ }^{3}$ \\ ${ }^{1}$ Instituto de Pesquisas Cananéia \\ ${ }^{2}$ Departamento de Ecologia e Zoologia, Universidade Federal de Santa Catarina \\ ${ }^{3}$ Laboratório de Vida Selvagem, Embrapa-Pantanal \\ *Autor para correspondência \\ Rua Brigadeiro Franco, 2480, apt ${ }^{\circ}$ 181, CEP 80250-030, Curitiba - PR, Brasil \\ rfusco79@yahoo.com.br
}

Submetido em 15/01/2008

Aceito para publicação em 02/07/2008

\section{Resumo}

Este é o primeiro estudo sobre a distribuição e abundância relativa do jacaré-de-papo-amarelo na Ilha de Santa Catarina. Foi estimada a abundância relativa do jacaré ao longo dos rios na Estação Ecológica de Carijós, além de verificar a sua ocorrência em toda a planície do Rio Ratones, noroeste da ilha. A média da abundância relativa foi de $0,25( \pm 0,07)$ jacarés/km percorrido, sendo obtida através de contagem noturna. Houve uma fraca correlação do número de jacarés com a temperatura do ar. Através de entrevistas com moradores locais e levantamento noturno da espécie em açudes e rios no entorno da unidade de conservação, foi verificado que os jacarés cobrem toda a planície do Rio Ratones, podendo ser encontrados em habitats naturais (rios, banhados, manguezais) e artificiais (canais de drenagem e açudes). Embora este estudo revele informações básicas sobre a distribuição do Caiman latirostris no noroeste da ilha, ele serve como base para futuras pesquisas.

Unitermos: Caiman latirostris, manguezal, conservação, ilha, Estação Ecológica de Carijós

\section{Abstract}

Abundance and local range of broad-snouted caiman (Caiman latirostris, Alligatoridae) in the northwest of Santa Catarina Island. This is the first report on the distribution and relative abundance of the broad-snouted caiman on Santa Catarina Island. The study estimated the relative abundance of caiman along the rivers at Estação Ecológica de Carijós, in addition to evaluating the occurrence of this species in the entire area of the Ratones River plain on the northwestern portion of the island. The mean relative abundance obtained by nocturnal counts was 0.25 $( \pm 0.07)$ caiman $/ \mathrm{km}$ surveyed. There was a weak correlation between the number of caimans and the air temperature. Based on interviews with the local community and nocturnal surveys of caimans in rivers and reservoirs surrounding the protected area, we concluded that the range occupied by caimans covered the entire area of the Ratones river plain, inhabiting natural habitats (rivers, mangroves, swamps) as well as artificial habitats (reservoirs and water channels). Although this study provides basic information about the broad-snouted caiman population on this part of the island, it is aimed mainly at providing guidance for future research.

Key words: Caiman latirostris, mangrove, conservation, island, Estação Ecológica de Carijós 


\section{Introdução}

O jacaré-de-papo-amarelo, Caiman latirostris, é um crocodiliano de tamanho médio $(2 \mathrm{~m})$, com uma distribuição geográfica restrita ao leste da América do Sul, incluindo o norte da Argentina, norte do Uruguai, leste do Brasil, sul da Bolívia e sul do Paraguai (Verdade e Piña, 2006). A espécie pode ser encontrada em manguezais, pântanos e banhados, junto de habitats associados com numerosos e pequenos rios que drenam para o Oceano Atlântico (Verdade, 1998). A presença da espécie também foi documentada em manguezais de ilhas costeiras no sudeste do Brasil (Moulton, 1993; Moulton et al., 1999). No Brasil, há uma carência de informações sobre a distribuição atual e o tamanho populacional do Caiman latirostris, tornando-se prioridade os estudos sobre sua ecologia populacional (Verdade, 1998).

Há relatos da ocorrência dessa espécie em rios, manguezais, banhados e restingas da Ilha de Santa Catarina, localizada na costa sul do Brasil. Visando documentar informações populacionais do jacaréde-papo-amarelo, foram investigados os locais de ocorrência e a abundância relativa na planície do Rio Ratones, a noroeste da ilha.

\section{Material e Métodos}

A planície do Rio Ratones, com uma área de 9.287ha, está localizada entre as coordenadas $48^{\circ} 31^{\prime} 48^{\prime \prime}$ e $48^{\circ} 25^{\prime} 06^{\prime \prime} \mathrm{W}$ e $27^{\circ} 25^{\prime} 48^{\prime \prime}$ e $27^{\circ} 31^{\prime} 48^{\prime \prime}$. É É drenada pelo rios Ratones, Papaquara e Veríssimo, além de inúmeros canais artificiais de drenagem. Nesta planície está localizada a Estação Ecológica de Carijós (ESEC de Carijós), no Manguezal de Ratones, junto à Baía Norte, com uma área de $625 \mathrm{ha}$. As áreas de planície são ocupadas por vegetação de manguezal e restinga, destacando-se áreas de banhados, além de pastagens e áreas cultivadas. Na década de 1960, a planície do Rio Ratones sofreu uma redução de $50 \%$ da sua área original em conseqüência das obras de drenagem realizadas pelo Departamento Nacional de Obras e Saneamento (DNOS) para fins diversos, tais como recuperação de áreas para agricultura, saneamento, construção de rodovias e expansão urbana. Em virtude das retificações de leito e assoreamento, o Rio Ratones perdeu 24\% de sua extensão original e a profundidade média hoje é de $1 \mathrm{~m}$, em contraste às profundidades de até $8 \mathrm{~m}$, registradas antes das obras de drenagem (Fidélis, 1998).

Para acessar a abundância relativa do jacaré-depapo-amarelo na ESEC de Carijós foi utilizado o método de contagem noturna com a utilização de uma lanterna com facho de luz forte de foco concentrado (Mourão e Campos, 1995; Sánchez et al., 1996; Da Silveira et al., 1997; Platt e Thorbjarnarson, 2000). Utilizou-se uma embarcação de alumínio (4,5m de comprimento), movida por um motor de popa (9,9 HP), com a qual foram percorridas rotas fixas a uma velocidade constante de $9 \mathrm{~km} / \mathrm{h}$. Foram realizadas dez excursões noturnas (dez noites) entre fevereiro e junho de 2002, sendo percorridos $7,77 \mathrm{~km}$ em cada excursão, ao longo do Rio Ratones $(4,4 \mathrm{~km})$ e parte do Rio Veríssimo $(3,37 \mathrm{~km}$ dos $4,6 \mathrm{~km}$ de extensão total), os quais deságuam e se conectam na Baia Norte. A cada excursão, os jacarés foram contabilizados apenas na ida. Para estimar a abundância relativa, em cada excursão dividiu-se o número de jacarés observados por $\mathrm{km}$ percorrido. A seleção das amostras não foi ao acaso, porque os rios eram os ambientes mais adequados para se encontrar jacarés-de-papo-amarelo durante a noite dentro da ESEC. Através da aproximação da embarcação, o tamanho aproximado (comprimento total) de cada jacaré observado foi estimado visualmente, seguindo as classes de tamanho consideradas por Mourão e Campos (1995). Todas as excursões foram feitas na maré intermediária (entre 0,3 e $0,9 \mathrm{~m}$ ), porque na maré baixa os bancos de areia ficam expostos, dificultando a locomoção da embarcação e impedindo o acesso a algumas áreas, como por exemplo, o Rio Veríssimo. Na maré alta, a área amostrada aumenta devido à expansão do rio que invade as áreas de mangues, dificultando a detecção de jacarés que podem estar entre as árvores do manguezal.

Para verificar se o número de jacarés observado variava em relação à temperatura, foi obtida a temperatura média noturna do ar para cada excursão. Estes dados de temperatura foram fornecidos pelo Centro Integrado de Metereologia e Recursos Hídricos de Santa Catarina (CLIMERH) na Empresa de Pesquisa Agropecuária e Extensão Rural de Santa Catarina (EPAGRI), sendo 
referentes ao município vizinho de São José. Para a análise estatística utilizou-se um teste correlação de Pearson (Zar, 1999).

Ao longo do ano de 2002, no entorno da ESEC de Carijós, foram realizadas 18 entrevistas em nove comunidades, procurando-se obter informações sobre os locais de ocorrência do jacaré-de-papo-amarelo em toda a planície do Rio Ratones. Foram entrevistados moradores que vivem próximos de rios, banhados ou que possuem açudes em suas propriedades e que conhecessem a região por morarem há muitos anos no local. Os entrevistados foram indicados pelos moradores da comunidade ou por pesquisadores que trabalham na região. Também, no entorno da ESEC de Carijós, foram realizadas excursões noturnas de barco e a pé em trechos mais acessíveis ao longo dos rios Papaquara e Ratones e em três açudes para registrar a presença do jacaré, fazendo uma única excursão para cada local. Os registros de ocorrência da espécie dentro e fora da ESEC de Carijós foram posicionados geograficamente com o auxílio do GPS (Global Position System).

\section{Resultados e Discussão}

Na ESEC de Carijós, todos os jacarés avistados estavam junto às margens dos rios, com vegetação adjacente de mangue, pequenos trechos de Spartina spp. e/ou porções de restinga. Ao longo de 10 noites de amostragem, no rio Veríssimo, o encontro com jacarés ocorreu somente dentro de um percurso de $500 \mathrm{~m}$ da Baia Norte pra dentro do rio, enquanto no Rio Ratones, eles foram detectados em diferentes trechos ao longo do rio. Diferente do Rio Ratones, o Rio Veríssimo é mais estreito e à medida que se distancia da Baia Norte, a vegetação fica mais densa nas bordas do rio, o que poderia estar afetando a detecção dos jacarés ou, a probabilidade de ocorrência destes animais realmente é baixa nestes trechos. Constatamos uma média de dois jacarés avistados por noite (variando de 0 a 6), com uma abundância-relativa ( \pm erro padrão) estimada de $0,25( \pm 0,07)$ jacarés $/ \mathrm{km}$ percorrido. $\mathrm{O}$ valor encontrado apresenta resultados similares aos obtidos por Mourão e Campos (1995) no Rio Paraná e seus afluentes, que variou de 0,28 a 0,07 jacarés $/ \mathrm{km}$. A abundância relativa encontrada nos dois trabalhos parece baixa quando comparada com outras espécies de crocodilianos (Sánchez et al., 1996; Da Silveira et al., 1997; Platt e Thorbjarnarson, 2000). Verificamos a ocorrência de um jacaré jovem, com comprimento total entre 0,3 e $0,5 \mathrm{~m}$. Este registro foi observado durante cinco noites (cinco avistamentos), sempre no mesmo local, sendo possivelmente o mesmo indivíduo. Dos outros 15 avistamentos, em somente 10 destes nós conseguimos estimar o tamanho. Os jacarés tinham de 1,0 a 1,5m de comprimento total, sendo provavelmente indivíduos adultos.

Variações observadas no número de jacarés em função da temperatura ambiental têm sido documentadas em alguns estudos com espécies de crocodilianos selvagens, evidenciando que este fator ambiental pode ter implicações diretas no monitoramento populacional (Lang, 1987; Da Silveira et al., 1997). Sob condições controladas em cativeiro, no entanto, Sarkis-Gonçalves et al. (2004) verificaram que as condições climáticas como chuva, vento e temperatura ambiente (do ar e da água) não influenciaram a contagem de jacaré-de-papoamarelo. Por outro lado, quanto menor a luminosidade da lua e menor o tamanho do jacaré, maior é a acurácia e precisão na contagem.

Ao longo dos rios da ESEC de Carijós, encontramos uma fraca correlação entre o número de jacarés com a temperatura média noturna do ar: coeficiente da correlação de Pearson $=0,67 ; \mathrm{p}=0,03$ (Figura 1). Evidentemente, um estudo mais prolongado é necessário pra testar se variações climáticas, estrutura do habitat, tamanho corporal, luminosidade da lua e teor de salinidade da água (no caso de sistemas estuarinos) influenciam ou não na contagem noturna de jacarés a fim de compreender a ecologia desta espécie na natureza e na tentativa de alcançar uma maior precisão na contagem de jacarés durante um monitoramento populacional.

Com base nas entrevistas foi constatada a ocorrência de jacarés no entorno da ESEC de Carijós nos rios (Ratones, Veríssimo e Papaquara), banhados, canais de drenagem e açudes. Entrevistados que possuíam açudes em suas propriedades relataram a presença de jacarés nestes locais. Também houve relatos da 
presença de jacarés em açudes localizados dentro de clubes esportivos, como por exemplo, o Jurerê Esporte Clube, localizado na praia de Jurerê. Os entrevistados também relataram a presença de ninhos nas margens de açudes e canais de drenagem. Próximo à nascente do Rio Ratones, moradores afirmaram ter visto jacarés adultos com freqüência e, algumas vezes, filhotes.

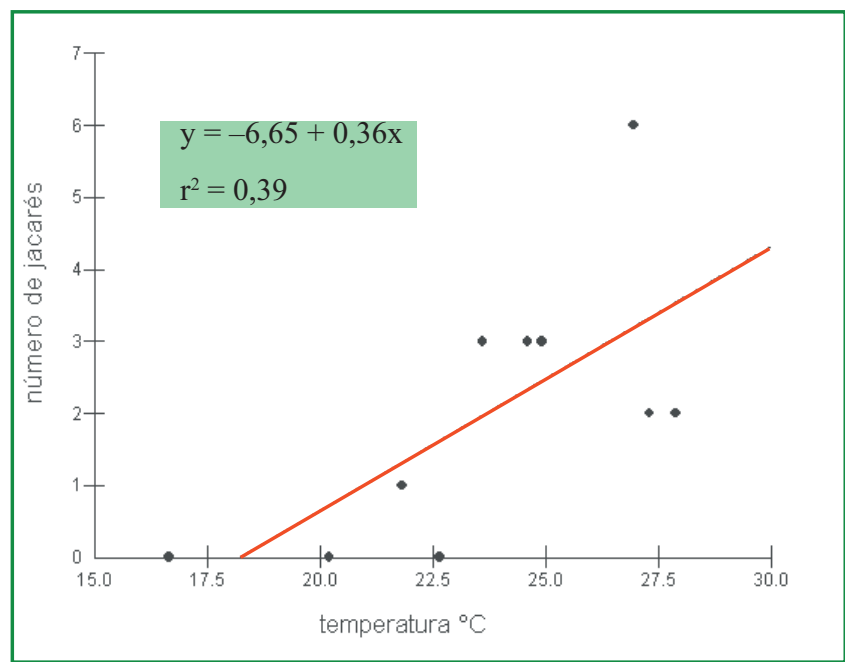

FIGURA 1: Relação entre o número de avistamentos de jacaré e a temperatura $\left({ }^{\circ} \mathrm{C}\right)$ do ar, durante as excursões noturnas ao longo dos rios na Estação Ecológica de Carijós, noroeste da Ilha de Santa Catarina.

Nas excursões complementares feitas no entorno da ESEC de Carijós foi encontrado um jacaré no Rio Papaquara, um no Rio Ratones e quatro em um único açude, sendo que nos outros dois nenhum jacaré foi encontrado. Os pontos de avistamento do jacaré-de-papoamarelo (dentro e fora da ESEC de Carijós) e os pontos de ocorrência indicados pelos entrevistados distribuem-se por toda a planície do Rio Ratones (Figura 2).

Verdade (1997) já havia presenciado uma aparente colonização da espécie em ambientes antrópicos, como açudes e lagoas artificiais, próximas a habitações humanas. O crescimento da urbanização na planície do Rio Ratones é intenso. Muitas áreas de banhado e de vegetação flutuante estão sendo reduzidas ou aterradas pela expansão urbana, principalmente nas comunidades mais ao norte da ilha. A conexão entre os rios, córregos, canais de drenagem e banhados que permeiam áreas de manguezais e restingas podem estar comprometidas, interferindo na capacidade de dispersão, alimentação e reprodução do jacaré-de-papo-amarelo. A preservação dos habitats naturais e a manutenção dos açudes e canais encontrados por toda planície são fatores importantes para mitigar o rápido crescimento da urbanização desordenada na planície do Rio Ratones e para a conservação do Caiman latirostris nesta região.

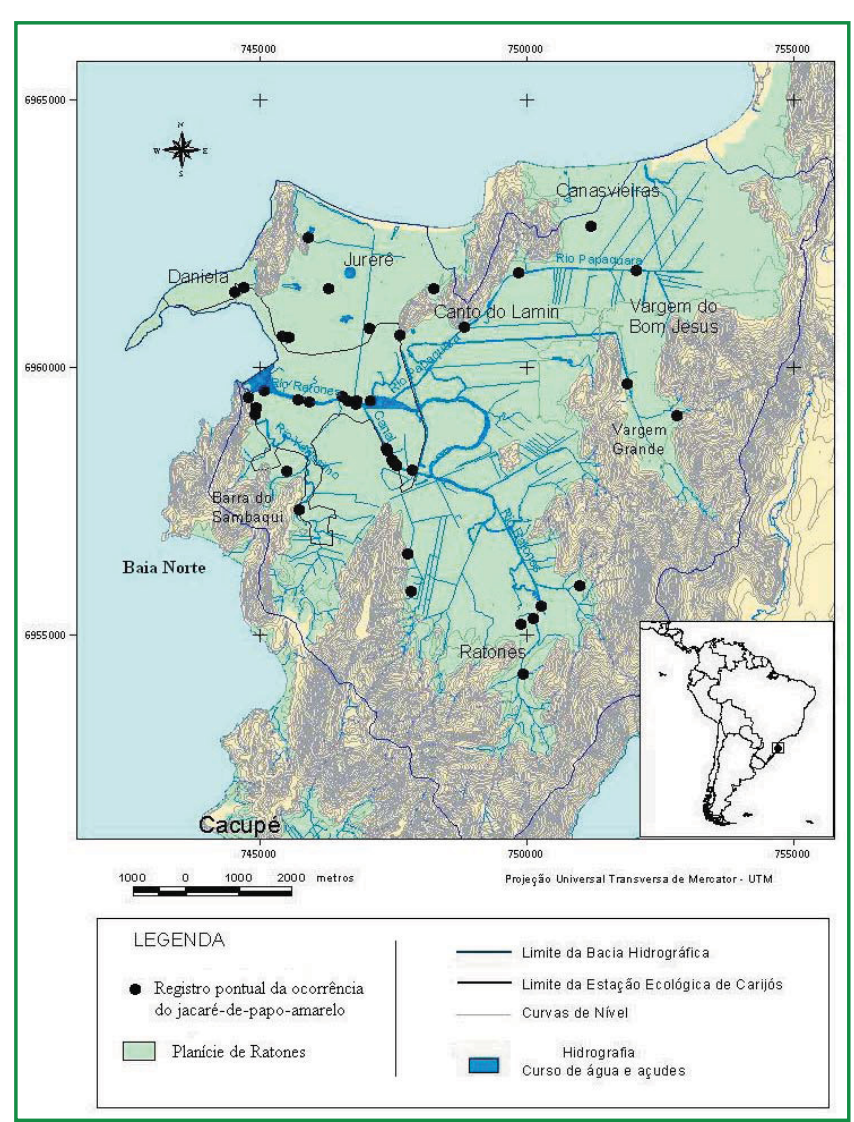

FIGURA 2: Distribuição dos pontos de ocorrência do jacaré-depapo-amarelo na planície do Rio Ratones, noroeste da Ilha de Santa Catarina.

Este é o primeiro estudo a documentar informações sobre a distribuição e abundância relativa do jacaréde-papo-amarelo em uma ilha do litoral do Estado de Santa Catarina. A partir deste estudo, recomenda-se que o monitoramento e a conservação populacional dessa espécie, incluindo a contagem noturna de indivíduos em cursos d'água artificiais (açudes, canais de drenagem) e naturais (rios, córregos, banhados), a localização e contagem de ninhos e a identificação de possíveis fatores que afetam a distribuição e abundância dos jacarés não se restrinjam apenas à área da Estação Ecológica, já que sua distribuição inclui toda a planície do Rio Ratones. 


\section{Agradecimentos}

Ao Instituto Carijós e ao IBAMA, por todo apoio a realização dessa pesquisa, em especial aos colegas Luiz Pimenta, Cláudio Mattos e José Olímpio. A Emygdio L. A. Monteiro-Filho e aos revisores anônimos pelas importantes sugestões durante a elaboração desse manuscrito.

\section{Referências}

Da Silveira, R.; Magnusson, W. E.; Campos, Z. 1997. Monitoring the distribution and breeding areas of Caiman crocodilus and Melanosuchus niger in the Anavilhanas Archipelago, central Amazonia, Brasil. Journal of Herpetology, 31 (4): 514-520.

Fidélis, F. N. L. 1998. Uma abordagem sobre as profundas modificações na morfometria fluvial da Bacia Hidrográfica do Rio Ratones-Florianópolis/SC, em um período de 40 anos e suas conseqüências. Dissertação de Mestrado, Universidade Federal de Santa Catarina, Florianópolis, Brasil, 255pp.

Lang, J. W. 1987. Crocodilan behaviour: implications for management. In: Webb, G. J. W.; Manolis, S. C. \& Whitehead, P. J. (eds) Wildlife and management: Crocodiles and alligators. Surrey Beaty Pty. Ltd., Chipping Norton, Australia, p.9-21.

Moulton, T. P. 1993. O programa sobre ecologia do jacaré-de-papoamarelo (Caiman latirostris) no CEPARNIC, Ilha do Cardoso, São Paulo, Brasil. Anais do III Workshop sobre Conservação e Manejo do Jacaré-de-papo-amarelo (Caiman latirostris), Piracicaba, Brasil, p.133-134.
Moulton, T. P.; Magnusson, W. E.; Melo, M. T. Q. 1999. Growth of Caiman latirostris inhabiting a coastal environment in Brazil. Journal of Herpetology, 33 (3): 479-484.

Mourão, G.; Campos, Z. 1995. Survey of broad-snouted caiman Caiman latirostris, marsh deer Blastocerus dichotomus and capybara Hydrochaeris hydrocaeris in the area to be inundated by Porto Primavera dam, Brazil. Biological Conservation, 73 (1): 27-31.

Platt, S. G.; Thorbjarnarson, J. B. 2000. Population status and conservation of Morelet's crocodile, Crocodylus moreletii, in northern Belize. Biological Conservation, 96 (1): 21-29.

Sánchez, J.; Bolaños, J. R.; Piedra, C. L. 1996. Población de Crocodylus acutus (Crocodylia: Crocodylidae) em dos rios de Costa Rica. Revista Biologia Tropical 44 (2): 835-840.

Sarkis-Gonçalves, F.; Castro, A. M. V.; Verdade, L. M. 2004. The influence of weather conditions on caiman night-counts. In: Crocodiles. Proceedings of the 17th Working Meeting of the Crocodile Specialist Group. IUCN - The World Conservation Union, Gland, Switzerland, p.387-393.

Verdade, L. M. 1997. Manejo e conservação do jacaré-de-papoamarelo (Caiman latirostris) em São Paulo, Brasil. In: ValladaresPádua, C. B.; Bodmer, R. E. \& Cullen, L. Jr. (eds). Manejo de vida silvestre para a conservação. Sociedade Civil Mamirauá, Manaus, Brasil, p.222-232.

Verdade, L. M. 1998. Caiman latirostris. In: Ross, J. P. (ed.). Revised action plan for crocodiles. IUCN - The World Conservation Union, Gland, Switzerland, p.18-20.

Verdade, L. M.; Piña, C. I. 2006. Caiman latirostris. Catalogue of American Amphibians and Reptiles, 833: 1-21.

Zar, J. H. 1999. Biostatistical analysis. $4^{\text {th }}$ ed. Prentice-Hall, New Jersey, USA, 663pp. 